\title{
OSALEJATE ARVAMUSTE MUUTUMINE ARGUMENTEERIMISDIALOOGIS
}

\author{
Mare Koit
}

Ülevaade. Artiklis käsitletakse argumenteerimisdialoogi mudelit, mille koosseisu kuulub osaleja arvamustel põhinev arutlusmudel. Dialoogi alustaja taotleb vestluspartneri otsust teatava tegevuse tegemise kohta. Mõlemad osalejad esitavad argumente, kusjuures argumendi valik sõltub, ühelt poolt, arvamustest tegevuse positiivsete ja negatiivsete aspektide ning tarvilike ressursside kohta, teiselt poolt aga nendel arvamustel põhineva arutluse tulemusest. Osalejate rollid dialoogis on erinevad. Dialoogi alustaja kasutab partnerimudelit, mis koosneb hüpoteetilistest arvamustest partneri kohta, kes peaks otsustama tegevuse tegemise üle. Samas kasutab partner arutlusprotsessis oma tegelikke arvamusi. Mõlemaid mudeleid ajakohastatakse dialoogi käigus vastavalt esiletoodud argumentidele. Artiklis vaadeldakse juhtumianalüüsi kaudu, kuidas osalejate arvamused dialoogi vältel muutuvad. Näited põhinevad eksperimentidel olemasoleva dialoogsüsteemiga.*

Võtmesõnad: argumenteerimisdialoog, arutlusmudel, osalejate arvamused, eesti keel

\section{Sissejuhatus}

Dialoogsüsteem (DS) ehk konversatsiooniagent on arvutisüsteem, mis suhtleb inimesega teksti, kõne, graafika, žestide jt suhtlusvahendite abil (Jurafsky, Martin 2009: ptk 24). Kõige levinumad on kõnepõhised DS-id, mis annavad kasutajale infot näiteks bussi- või rongigraafikute kohta. Siinses artiklis ei käsitleta siiski infodialooge, vaid keskendutakse dialoogile, mis sisaldab argumenteerimist teatud tegevuse tegemise poolt või vastu. Eesmärgiks on jälgida, kuidas osalejad saavad dialoogi käigus esitatavate argumentidega teineteise algseid arvamusi muuta.

Eeldatakse, et osalejad on $A$ ja $B$ ning üks neist, $A$, algatab dialoogi, esitades oma partnerile $B$ ettepaneku teha (või tegemata jätta) tegevus $D$. Kui $B$ keeldub, siis püüab $A$ teda dialoogi käigus mõjutada, tuues esile mitmesuguseid argumente

* Artikli valmimist on toetanud Eesti Teadusagentuur (projekt IUT20-56 "Eesti keele arvutimudelid"). 
$D$ tegemise poolt (või vastu). Osaleja $A$ argumendid põhinevad partnerimudelil: $A$ ettekujutusel $B$ arvamustest tegevuse $D$ mitmesuguste aspektide kohta. Partner $B$ võib esitada vastuargumente. Vastuargumendid näitavad, missugused $A$ arvamused $B$ kohta on valed ja kuidas $A$ peab seetõttu muutma partnerimudelit.

Uurides dialoogi modelleerimist arvutil, võib vaadelda erinevaid stsenaariume: a) $A$ on konversatsiooniagent (DS) ja $B$ on inimene-kasutaja; b) $A$ on kasutaja ja $B$ on agent; c) nii $A$ kui ka $B$ on agendid. Erinevad stsenaariumid võimaldavad analüüsida ja modelleerida mõlema dialoogis osaleja käitumist, et mõista, kuidas nende arvamused dialoogi kestel partneri argumentide mõjul muutuvad. Artikli aluseks on eksperimentaalne DS, mis võib suhtluses kasutajaga täita $\operatorname{kas} A$ või $B$ rolli.

Artikkel on üles ehitatud järgmiselt. 2. osas esitatakse argumenteerimisdialoogi mudel. Demonstreerimaks, kuidas konversatsiooniagent ajakohastab vestluse käigus partnerimudelit (s.o oma arvamusi partneri kohta), analüüsitakse 3. osas näitedialoogi. 4. osas vaadeldakse sedasama näidet kasutades, kuidas argumentide toimel muutuvad ka partneri tegelikud arvamused. Näited põhinevad eksperimentidel olemasoleva DS-iga. 5. osas arutletakse partnerimudeli ja tegelike arvamuste erinevuste üle. 6. osas tehakse kokkuvõtteid.

\section{Argumenteerimisdialoogi mudel}

Argumenteerimisdialoogi mudelit on täpsemalt kirjeldatud artiklites (Koit, Õim 2003, Koit, Õim 2014a). Järgneva parema mõistmise huvides on esitatud see siin siiski kokkuvõtlikult.

Olgu dialoogis osalejad (kas inimesed või konversatsiooniagendid) $A$ ja $B$. Olgu $A$ dialoogi algataja ja olgu tema suhtluseesmärk " $B$ otsustab teha tegevuse $D$ " või vastavalt, “ $B$ otsustab mitte teha tegevust $D$ ”. Osaleja $B$ suhtluseesmärk võib ühtida $A$ eesmärgiga või olla sellele vastupidine. Suhtluses püüab $A$ mõjutada partnerit $B$ vastu võtma sellist otsust, mis vastab $A$ suhtluseesmärgile.

Initsiaatoril $A$ on partneri $B$ mudel - ettekujutus $B$ arvamustest tegevuse erinevate aspektide kohta. Partnerimudel võimaldab tal eeldada, et $B$ nõustub aktsepteerima tema suhtluseesmärki. Konstrueerides oma esimest vooru, valib $A$ dialoogiaktid (nt soov, ettepanek, küsimus jne, sõltuvalt oma mudelist $B$ kohta) ja määrab nende verbaalse vormi (lausungid). Partner $B$ analüüsib $A$ vooru ja ekstraheerib sellest $A$ suhtluseesmärgi. Oma otsuse tegemiseks - teha $D$ või mitte - käivitab ta (oma peas) arutlusprotseduuri. Selle käigus kaalub $B$ oma ressursse $D$ tegemiseks, $D$ positiivseid ja negatiivseid aspekte ja lõpuks võtab vastu otsuse. Selle teatavakstegemiseks valib $B$ omakorda dialoogiaktid (nõustumine, keeldumine vms) ja nende verbaalse vormi. Kui $B$ nõustub, siis on $A$ oma suhtluseesmärgi saavutanud. Kui $B$ keeldub, siis peab $A$ muutma oma partnerimudelit, mis ei olnud kooskõlas tegelikkusega, ja leidma uusi argumente, veenmaks partnerit tegema taotletavat otsust. Oma keeldumisele võib $B$ lisada argumente. Need (vastu)argumendid annavad infot arutlusprotsessi kohta, mis viis $B$ (negatiivse) otsuseni. $A$ kasutab neid argumente oma jooksva partnerimudeli ajakohastamiseks. 


\subsection{Arutlusmudel}

Arutlusmudel koosneb kahest osast: 1) (inimese) motivatsioonisfääri mudelist; 2) arutlusprotseduuridest.

Motivatsioonisfääri mudeli saab esitada (arutluse all oleva tegevuse $D$ aspektidele omistatavate) "kaalude" vektorina, mille komponentidel on arvulised väärtused:

$\boldsymbol{w}=$ (w(ressursid), w(meeldiv), w(ebameeldiv), w(kasulik), w(kahjulik), w(kohustuslik), w(keelatud), w(karistus-teha), w(karistus-mitte-teha)).

Siin tähistavad w(meeldiv) jne $D$ meeldivate jne aspektide kaalu. Edasi, $\mathrm{w}($ ressursid $)=1$, kui subjektil on olemas kõik $D$ tegemiseks vajalikud ressursid (vastupidisel juhul o); $\mathrm{w}($ kohustuslik) $=1$, kui $D$ tegemine on arutleva subjekti jaoks kohustuslik (vastasel korral o) ja w(keelatud) $=1$, kui $D$ on subjekti jaoks keelatud (muidu o), ning w(karistus-teha) - keelatud $D$ tegemisele järgnevat karistust ja w(karistus-mitte-teha) kohustusliku D mittetegemisele järgnevat karistust. Selguse mõttes tuleks vektori esituses tähistada ka tegevus $(D)$, kuid siin on sellest loobutud, sest vaadeldakse ühtainsat kindlat tegevust.

Suhtlusprotsessis kasutavad osalejad kahte (erinevat) motivatsioonisfääri mudelit (kaalude vektorit). Vektor $\boldsymbol{w}^{A B}$ esitab $A$ arvamusi $B$ arvamuste kohta ja seda kasutatakse partnerimudelina. Vektor $\boldsymbol{w}^{B}$ esitab $B$ tegelikke hinnanguid $D$ aspektidele (mille täpseid väärtusi $A$ ei tea) ning seda kasutatakse $B$ iseenda mudelina. Artiklis vaadeldakse, milliseid muudatusi osalejad teevad nendes mudelites dialoogi käigus esitatud argumentide toimel.

Arutlusmudeli teine osa koosneb arutlusprotseduuridest, mis eeldatavasti reguleerivad inimese arutlusi tegevuste kohta. Iga arutlusprotseduur koosneb sammudest, mida subjekt peab arutluse käigus läbima, ja iga samm seisneb teatavate kaalude summeerimises ja võrdlemises. Arutlusprotseduuri tulemuseks on otsus: teha (või mitte teha) $D$. Motivatsioonisfääri mudelis eristatakse kolme põhifaktorit, mis reguleerivad subjekti arutlust tegevuse $D$ tegemise kohta. Esiteks, subjektil on soov teha $D$, kui $D$ tegemise meeldivad aspektid ületavad ebameeldivaid; teiseks, subjektil on vaja teha $D$, kui kasulikud aspektid ületavad kahjulikke, ja kolmandaks, subjekt peab tegema $D$, kui see on kohustuslik ja tegematajätmine toob kaasa karistuse.

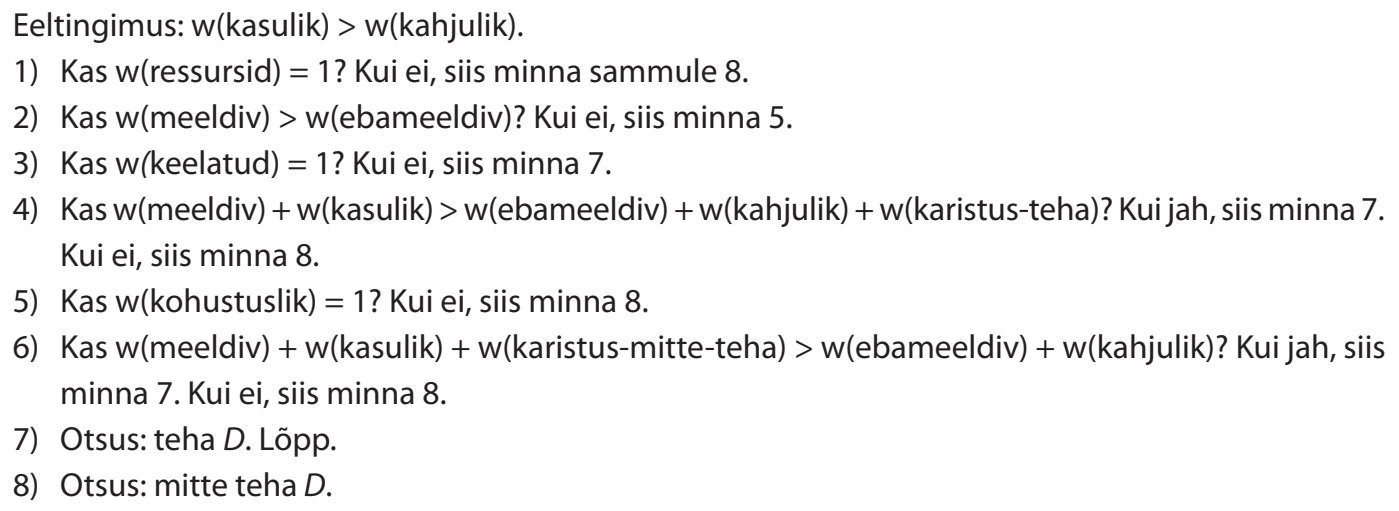

Joonis 1. Arutlusprotseduur VAJA 
Arutlusprotseduur sõltub faktorist, mis selle käivitab. Näiteks on joonisel 1 esitatud samm-algoritmina arutlusprotseduur VAJA, mille käivitamise eelduseks on, et arutleva subjekti jaoks on $D$ kasulikkus suurem kui kahjulikkus (vt ka Koit, Õim 2014b). ${ }^{1}$

\subsection{Suhtlusstrateegiad ja -taktikad}

Suhtlusstrateegia all mõistetakse algoritmi, mida suhtluses osaleja kasutab oma suhtluseesmärgi saavutamiseks. Et saavutada suhtluseesmärk tegevuse $D$ tegemisele suunatud argumenteerimisdialoogis, esitab kumbki osaleja argumente ning teeb seda süstemaatilisel viisil. Näiteks kui suhtluse algataja $A$ suhtluseesmärk on “ $B$ teeb $D$ ”, siis võib ta rõhutada $D$ meeldivaid aspekte, püüdes käivitada partneri peas soovist lähtuvat arutlust (s.o ahvatleda partnerit tegema $D$ ), või kasulikke aspekte, püüdes käivitada vajadusest lähtuvat arutlust (s.o veenda partnerit), või kohustusliku $D$ tegematajätmisele järgnevat karistust, rõhutades, et partner peab tegema tegevuse (s.o ähvardada partnerit tegema $D$ ). Neid suhtlusstrateegia realiseerimise konkreetseid viise nimetatakse suhtlustaktikateks (Koit 2015, Koit, Õim 2014a).

\subsection{Argumenteerimisdialoog}

Nagu sissejuhatuses öeldud, põhineb artikkel DS-il, mis suhtleb kasutajaga (kirjalikus) eesti keeles, kusjuures ühel juhul on DS dialoogi initsiaatori $A$ rollis ja teisel juhul $B$ rollis. Sellega seoses saab vaadelda argumenteerimisdialoogi nii $A$ kui ka $B$ modelleerimise seisukohalt. Olgu mõlema osaleja käsutuses kindel arutlusprotseduuride hulk. Kasutagu mõlemad fikseeritud hulka dialoogiakte ja nende väljendamiseks etteantud lausungeid, mis on semantiliselt klassifitseeritud. Näiteks lausungite hulk $\mathrm{P}_{\text {ressursid_olemas }}$ on selle asjaolu väljendamiseks, et tegevuse $D$ tegemiseks on olemas kõik ressursid (nt Firma katab su erakorralised kulud), hulk $\mathrm{P}_{\text {suurenda_meeldivust }}$ tegevuse $D$ tegemise meeldivuse rõhutamiseks (nt $S a$ saad kohtuda huvitavate inimestega), hulk $\mathrm{P}_{\text {ressursid_puuduvad selle väljendamiseks, et }}$ mõned $D$ tegemiseks vajalikud ressursid puuduvad (nt Mul ei ole sobivat riietust),

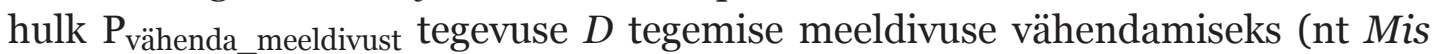
selles reisis on meeldivat?) jne. Seega eeldatakse (vaadeldavas realisatsioonis), et keelelist analüüsi ja sünteesi ei tehta. (See asjaolu tingib ühtlasi, et DS-iga genereeritud dialoogid ei tarvitse olla päris sidusad.)

Näiteks kui $A$ eesmärk on " $B$ teeb $D$ " ja $B$ eesmärk on " $B$ ei tee $D$ ”, siis dialoogi alustades genereerib $A$ partnerimudeli $\boldsymbol{w}^{A B}$ ja määrab kasutatava suhtlustaktika $t$ (nt veenmine). Vastavalt fikseerib ta ka arutlusprotseduuri $R$, mida üritab käivitada partneris $B$ (näiteks VAJA). Osalejal $B$ on iseenda mudel $\boldsymbol{w}^{B}$ (mille komponentide täpseid väärtusi $A$ muidugi ei tea). $B$ määrab omakorda arutlusmudeli $R^{B}$, mida ta hakkab kasutama, kui otsustab $D$ tegemise üle ja mis ei pea olema seesama, mida $A$ oma suhtlustaktikaga üritab käivitada (nt SOOV, kui vastavad eeltingimused on täidetud), samuti oma suhtlustaktika $t^{B}$.

Järgnevas dialooginäites on $A$ firmajuht ja $B$ firma töötaja, kes samal ajal õpib ülikoolis. $A$ esitab argumente, veenmaks $B$-d tegema $D$ (reisima N-sse, et sõlmida

Arutlusprotseduuri võib käsitleda ka kui argumenteerimist teatava otsuse kasuks ning esitada spetsiaalse loogilise formalismi abil (nt Amgoud jt 2015). (Autor tänab retsensenti viidete eest.) 
seal leping). Ta suudab tõrjuda $B$ vastuargumente ja veenda teda vastu võtma taotletavat otsust.

1. A: Oleks hea, kui sa nõustuksid sõitma $N$-sse. Meie firmal on seal vaja sõlmida leping.

2. B: Mul pole sobivat riietust.

3. A: Firma katab su erakorralised kulud. Sa saad firmale kasulik olla.

4. B: Mul võivad tekkida probleemid ülikooliga.

5. A: Sellega on korras - sinu eksamiperioodi pikendatakse. Firma hindab sinu panust.

6. B: Olgu, ma lähen.

7. A: Olen rõ̃omus.

\section{Partnerimudeli ajakohastamine}

DS-i tähtsaim komponent, mis juhib suhtlust, on dialoogihaldur. Ta analüüsib sisendit, ajakohastab dialoogi seisundeid, otsustab järgmiste tegevuste üle ja genereerib väljundi (Bos jt 2003). Dialoogihaldurites kasutatakse nelja erinevat arhitektuuri: plaanipõhist, lõplikel automaatidel põhinevat, freimipõhist ja infoseisundipõhist (Jurafsky, Martin 2009: ptk 24). Komplitseerituim arhitektuur, mis kombineerib teisi lähenemisviise, on infoseisundipõhine (Traum, Larsson 2003, Young jt 2007). Infoseisund on keerukam mõiste kui staatilised seisundid, mida kasutab näiteks lõpliku automaadina realiseeritud dialoogihaldur. Infoseisundi koosseisu võivad kuuluda ka sellised mõisted nagu osalejate arvamused, kavatsused, plaanid jms. Artikli aluseks võetud rakenduses kasutatakse infoseisundite arhitektuuri (vt lähemalt Koit 2012). Konversatsiooniagendi infoseisundil on kaks osa: privaatne (ainult agendile kättesaadav info) ja jagatud (mõlemale osalejale kättesaadav info). Ühest infoseisundist teise liikumine toimub vastavalt värskendamisreeglitele, mida on mitut erinevat liiki.

Järgnevalt demonstreeritakse osas 2.3 toodud dialooginäite alusel partnerimudeli kasutamist ja ajakohastamist suhtluse käigus. (Siin ei käsitleta infoseisundi muude komponentide muutumist.) Esinegu konversatsiooniagent $A$ rollis. Olgu tema suhtluseesmärk saavutada $B$ otsus teha $D=$ "sõita $\mathrm{N}$-sse, et sõlmida seal leping”. Olgu $A$ valitud taktika veenmine ja olgu genereeritud partnerimudel $\boldsymbol{w}^{A B}=\left\{\mathrm{w}^{A B}\right.$ (ressursid) $=1, \mathrm{w}^{A B}$ (meeldiv $)=4, \mathrm{w}^{A B}$ (ebameeldiv $)=2, \mathrm{w}^{A B}($ kasulik $)=5$, $\mathrm{w}^{A B}($ kahjulik $)=2, \mathrm{w}^{A B}$ (kohustuslik) $=0, \mathrm{w}^{A B}$ (keelatud $)=0, \mathrm{w}^{A B}$ (karistus-teha $)=0$, $\mathrm{w}^{A B}$ (karistus-mitte-teha) $\left.=0\right\}$. Arutlusprotseduur VAJA (joonis 1, osa 2.1) annab sellel mudelil positiivse otsuse (teha $D$ ). Seega eeldab $A$ suhtlust alustades, et partner $B$ soostub tegema $D$.

$A$ algne infoseisund on järgmine.

Privaatne osa:

- $\quad$ partnerimudel $\boldsymbol{w}^{A B}=(1,4,2,5,2,0,0,0,0)$,

- $A$ valitud taktika - veenmine,

- $\quad A$ püüab käivitada $B$-s arutlusprotseduuri VAJA, mille eeldus on täidetud: $\mathrm{w}^{A B}$ (kasulik) $>\mathrm{w}^{A B}$ (kahjulik),

- alameesmärkide pinu (ingl last in, first out) sisaldab ainult veenmise nimiaspekti "kasulikkus", 
- $A$ käsutuses on dialoogiaktide hulk: \{ettepanek, väide ( $D$ erinevate aspektide kaalude suurendamiseks/vähendamiseks $B$ jaoks) jne\},

- lausungite hulk dialoogiaktide keeleliseks väljendamiseks: \{nt Firma katab su erakorralised kulud, Sa võid olla kasulik firmale jne\}.

Algse infoseisundi jagatud osa sisaldab

- arutlusprotseduurid SOOV, VAJA, PEAB jne,

- veenmise, ahvatlemise, ähvardamise jne taktikad,

- dialoogi ajalugu on tühi hulk.

Siin eeldatakse, et iga väide (argument), mis dialoogis esitatakse, suurendab (või vastavalt vähendab) vastava aspekti kaalu partnerimudelis täpselt ühe ühiku võrra.

$A$ algne suhtluseesmärk on, et $B$ otsustaks teha $D$. Et seda saavutada, esitab $A$ argumente $D$ tegemise kasuks ja tõrjub $B$ vastuargumente. $A$ ei tea $D$ aspektide tegelikke kaale $B$ iseenda mudelis $\boldsymbol{w}^{B}$. Pärast $B$ iga vastuargumenti peab $A$ ajakohastama mudelit $\boldsymbol{w}^{A B}$. Dialoogi lõpuks saavutab $A$ oma suhtluseesmärgi: $B$ nõustub tegema $D$. Arutlusprotseduur VAJA dialoogi lõpuks ajakohastatud partnerimudelil annab samuti positiivse otsuse. Tabel 1 demonstreerib samm-haaval, kuidas arvamused partnerimudelis dialoogi kestel muutuvad.

$A$ alustab dialoogi ettepanekuga $B$-le. Kasutades veenmise taktikat ja püüdes partneris käivitada arutlusprotseduuri VAJA, lisab $A$ oma ettepanekule argumendi $D$ tegemise kasulikkuse suurendamiseks (voor 1). Seega suurendab ta ka kasulikkuse algväärtust partnerimudelis ühe ühiku võrra. Kehtiv arutlusprotseduur VAJA annab sellel mudelil positiivse tulemuse. Partneri $B$ vastuargument (voor 2) aga näitab, et $B$-l puuduvad ressursid (Mul pole sobivat riietust), seega peab $A$ muutma kaalu w(ressursid): 1 asemel o. Nüüd peab $A$ järgmises voorus 3 leidma argumendi, mis näitaks, et ressursid on hangitavad: ta valib lausungi hulgast $\mathrm{P}_{\text {suurenda_ressursse }}$ (Firma katab su erakorralised kulud) ja - järgides ikka veenmise taktikat - lisab argumendi kasulikkuse suurendamiseks (Sa saad firmale kasulik olla). Ajakohastatud partneri mudelis on kaal $\mathrm{w}^{A B}$ (ressursid) nüüd 1 ja kaal $\mathrm{w}^{A B}$ (kasulik) suureneb 1 võrra. Arutlus ajakohastatud mudelis, mille $A$ "läbi mängib", annab positiivse otsuse. Ometi esitab $B$ järgmises voorus 4 uue vastuargumendi, viidates tegevuse kahjulikkusele: Mul võivad tekkida probleemid ülikooliga.

See voor vajab pikemat kommenteerimist. Miks $B$ väide kahjulikkuse kohta suurendab kaalu partneri mudelis 6 , aga mitte 1 võrra (tabel 1)? Kui vaadelda detailsemalt arutlusalgoritmi VAJA (osa 2.1), siis kuni selle hetkeni eeldas $A$, et $D$ ei ole $B$ jaoks keelatud. See eeldus aga osutub $B$ 4. vooru tõttu valeks, sest vastasel korral ei saaks $B$ esile tuua $D$ kahjulikkust (juhul kui ta arutleks protseduuri VAJA kohaselt, nagu $A$ eeldab). Järelikult võrdleb $B$ eeldatavasti kaale algoritmi 4. sammul ja seejärel jõuab negatiivse otsuseni. $B$ saab jõuda algoritmi 4 . sammuni ainult olles eelnevalt täitnud 3. sammu, kus ta leiab, et $D$ on tema jaoks keelatud ja $D$ tegemine toob kaasa karistuse. Järelikult peab $A$ muutma kaalu $\mathrm{w}^{A B}$ (keelatud) - o asemel 1 - ja suurendama kaalu $\mathrm{w}^{A B}$ (karistus-teha) partneri mudelis vähemalt 1 võrra. ("Optimistina" suurendab ta seda kaalu täpselt 1 võrra ja mitte enam.) Nüüd peab $A$ kontrollima, kuidas tuleb muuta mudelis kahjulikkuse kaalu, et jõuda negatiivse otsuseni nagu $B$. Arutlusalgoritmi VAJA kohaselt arvutab $A$ välja, et seda kaalu tuleb suurendada (vähemalt) 6 võrra. 


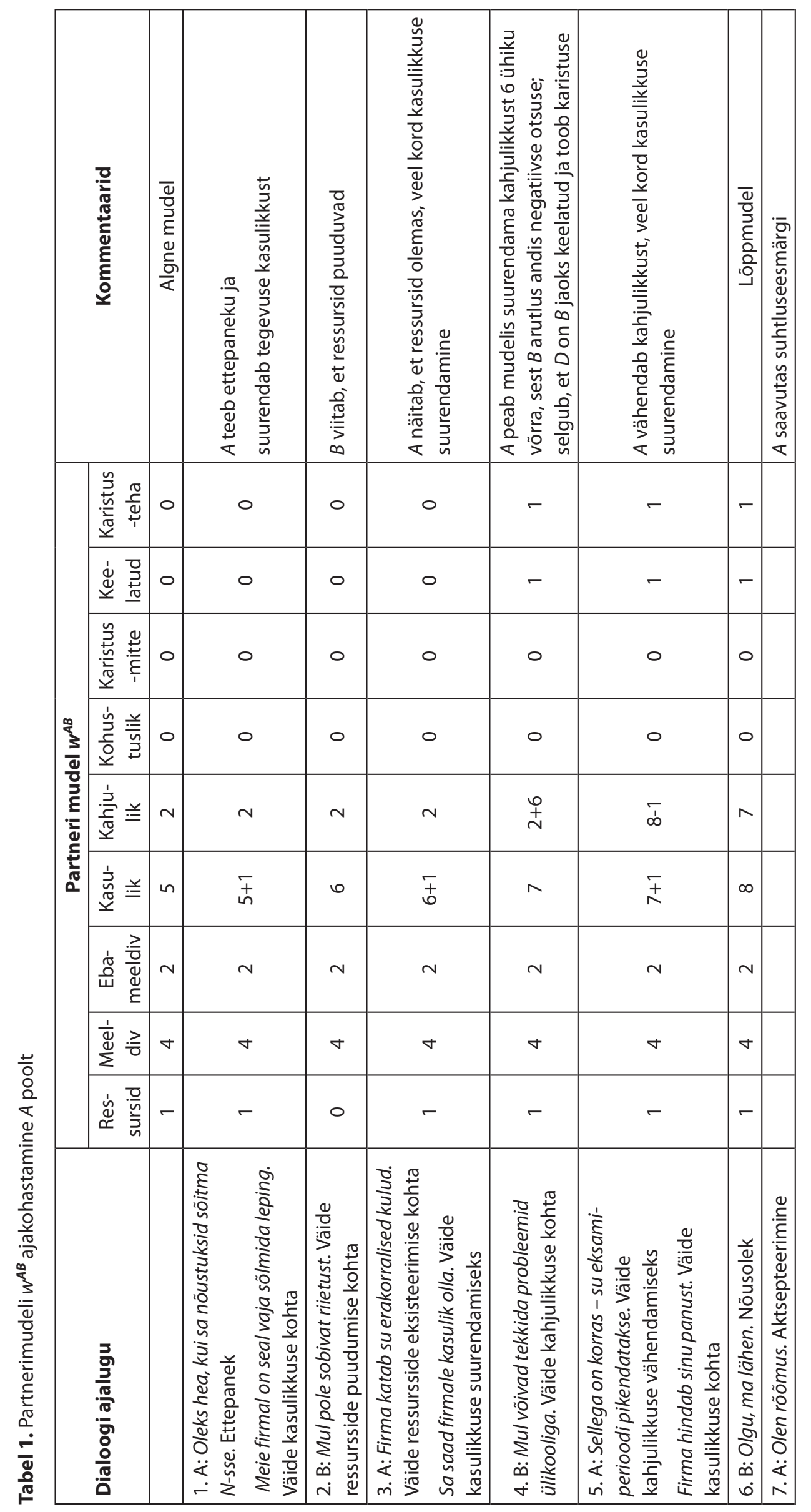


Reageerides $B$ vastuargumendile, vähendab $A$ kaalu w ${ }^{A B}$ (kahjulik) 1 võrra, esitades lausungi Sellega on korras - sinu eksamiperioodi pikendatakse, ja suurendab veel kord kaalu $\mathrm{w}^{A B}$ (kasulik), esitades lausungi Firma hindab sinu panust (voor 5). Arutlusprotseduur VAJA annab ajakohastatud partnerimudelil positiivse otsuse. Nüüd selgub, et $B$ jõudis sellesama otsuseni (voor 6). $A$ on saavutanud oma suhtluseesmärgi ja lõpetab dialoogi (voor 7).

\section{Iseenda mudeli ajakohastamine}

Tabelis 1 (osa 3) toodud näide iseloomustab partnerimudeli $\boldsymbol{w}^{A B}$ ajakohastamist argumenteerimisdialoogi käigus. Võrreldes esialgse mudeliga, millest $A$ lähtus dialoogi alustades, on muutunud nelja kaalu väärtused: $\mathrm{w}^{A B}$ (kasulik) 5 asemel 8, $\mathrm{w}^{A B}$ (kahjulik) 2 asemel $7, \mathrm{w}^{A B}$ (keelatud) ja $\mathrm{w}^{A B}$ (karistus-teha) mõlemad o asemel 1. Kõik need muudatused on tingitud $A$ argumentidest ja $B$ vastuargumentidest.

Tekib küsimus: kas dialoogi lõpuks saavutatud partnerimudel $\boldsymbol{w}^{A B}$ ühtib $B$ iseenda mudeliga $\boldsymbol{w}^{B}$, st kas $A$ on õigesti ära arvanud kõik $B$ mudelis olevad tegelikud kaalud? Vastus on eitav. Järgnev näide selgitab, miks nii.

Olgu vaatluse all uuesti näitedialoog osast 2.3 ja tabel 1 osast 3. Olgu $B$ konversatsiooniagent (mitte inimene-kasutaja, kes ei tarvitse rakendada kindlat arutlusalgoritmi) ja olgu tema iseenda mudel dialoogi alustades $\boldsymbol{w}^{B}=(0,6,4,3,4,0,0,1,3)$, st erinev mudelist $\boldsymbol{w}^{A B}$, mida kasutab $A$ (osa 3). Olgu $B$ suhtluseesmärk seesama mis $A$-l, st soovigu $B$ teha tegevust $D$. Et $D$ tegemise suhtes otsusele jõuda, peab $B$ käivitama oma mudelil arutlusprotseduuri, kontrollides ressursside olemasolu ning võrreldes $D$ tegemise positiivsete ja negatiivsete aspektide kaale. Kuidas $B$ valib arutlusprotseduuri? See sõltub eeltingimustest (vt lähemalt Koit, Õim 2014a).

Osas 2.1 on toodud protseduur VAJA (joonis 1), mida $A$ püüab $B$ peas käivitada (osa 3). See on rakendatav, kuna nii algses kui ka lõpuks kehtivas partnerimudelis $\boldsymbol{w}^{A B}$ on täidetud selle protseduuri eeltingimus $\boldsymbol{w}^{A B}$ (kasulik) $>\boldsymbol{w}^{A B}$ (kahjulik).

$B$ aga ei saa oma mudelis $\boldsymbol{w}^{B}$ käivitada sedasama protseduuri, sest $\boldsymbol{w}^{B}$ (kasulik) < $\boldsymbol{w}^{B}$ (kahjulik). Ta saab aga käivitada teise arutlusprotseduuri SOOV (samm-algoritm joonisel 2, vt ka Koit, Õim 2014a), mille eeltingimus on täidetud.

\footnotetext{
Eeltingimus: $w$ (meeldiv) $>$ w(ebameeldiv).

1) Kas w(ressursid) $=1$ ? Kui ei, siis minna sammule 11.

2) Kas w(meeldiv) $>$ w(ebameeldiv) $+w($ kahjulik)? Kui ei, siis minna 6.

3) Kas $w($ keelatud $)=1$ ? Kui ei, siis minna 10.

4) Kas $w($ meeldiv $)>w($ ebameeldiv $)+w($ kahjulik $)+w($ karistus_teha $)$ ? Kui jah, siis minna 10.

5) Kas $w($ meeldiv $)+w($ kasulik $)>w($ ebameeldiv $)+w($ kahjulik $)+w($ karistus_teha $)$ ? Kui jah, siis minna 10. Kui ei, siis minna 11.

6) Kas $w($ meeldiv $)+w($ kasulik $) \leq w($ ebameeldiv $)+w($ kahjulik) $)$ Kui ei, siis minna 9.

7) Kas $w($ kohustuslik) $=1$ ? Kui ei, siis minna 11 .

8) Kas $w($ meeldiv $)+w($ kasulik $)+w($ karistus-mitte-teha $)>w($ ebameeldiv $)+w($ kahjulik) ? Kui jah, siis minna 10. Kui ei, siis minna 11.

9) Kas w(keelatud) $=1$ ? Kui jah, siis minna 5 . Kui ei, siis minna 10.

10) Otsus: teha D. Lõpp.

11) Otsus: mitte teha D.
}

Joonis 2. Arutlusprotseduur SOOV 


\begin{tabular}{|c|c|c|c|c|c|c|c|c|c|c|}
\hline & 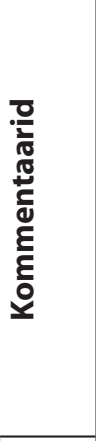 & 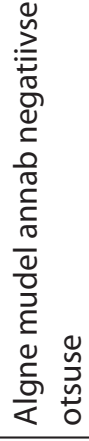 & 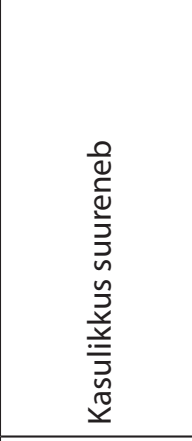 & 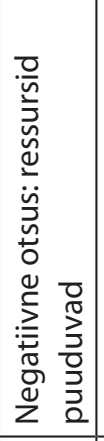 & 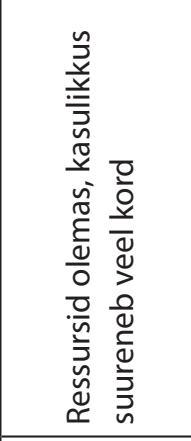 & 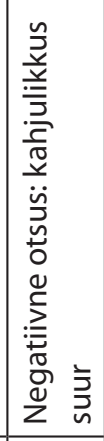 & 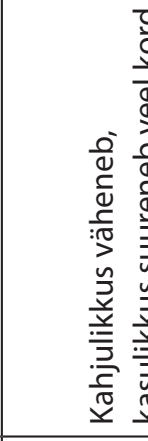 & & $\begin{array}{l}\overline{\overline{0}} \\
\frac{0}{2} \\
\frac{0}{0} \\
\frac{0}{0}\end{array}$ & 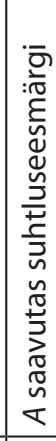 \\
\hline & 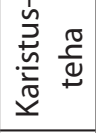 & $m$ & $m$ & $m$ & $m$ & $m$ & $m$ & & $m$ & \\
\hline & $\begin{array}{l}\frac{1}{d} \\
\frac{\sigma}{\Phi} \\
\frac{\partial}{2}\end{array}$ & - & - & - & - & - & - & & - & \\
\hline & 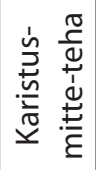 & 0 & 0 & 0 & 0 & 0 & 0 & & 0 & \\
\hline & 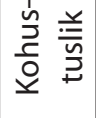 & 0 & 0 & 0 & 0 & 0 & 0 & & 0 & \\
\hline$\overbrace{}^{\frac{0}{0}}$ & 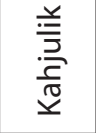 & $\nabla$ & $\nabla$ & $\nabla$ & $\sigma$ & $\sigma$ & $\bar{q}$ & & $m$ & \\
\hline & 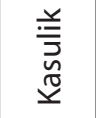 & $m$ & $\underset{m}{\mp}$ & $\nabla$ & $\Varangle$ & in & 舌 & & 0 & \\
\hline & 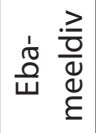 & $\nabla$ & $\nabla$ & $\nabla$ & $\nabla$ & $\nabla$ & $\sigma$ & & $\nabla$ & \\
\hline & $\frac{\frac{1}{\Phi}}{\sum^{\frac{N}{u}}} \geq$ & 0 & 0 & 0 & 0 & 0 & 0 & & 0 & \\
\hline & 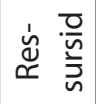 & 0 & 0 & 0 & - & - & - & & - & \\
\hline & $\begin{array}{l}\frac{3}{0} \\
\frac{3}{\pi} \\
\frac{0}{\pi} \\
\frac{0}{0} \\
\frac{0}{0}\end{array}$ & & 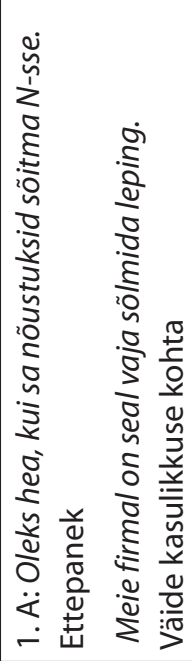 & 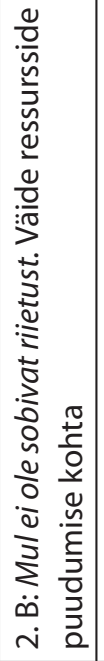 & 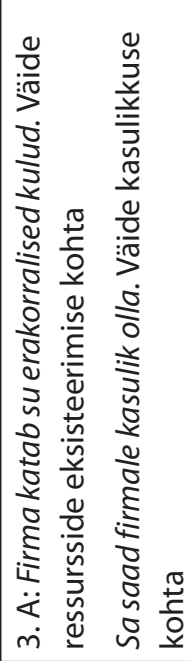 & 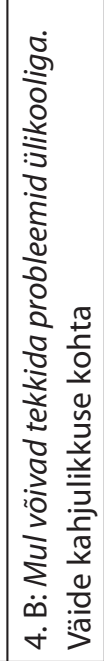 & 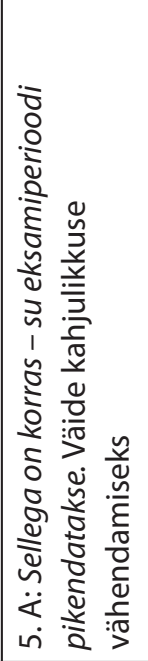 & 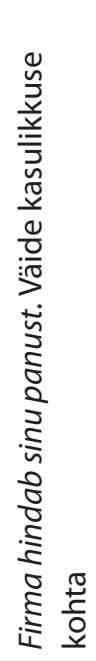 & 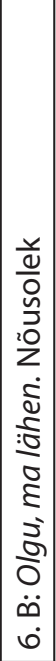 & 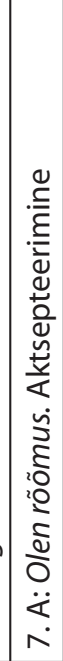 \\
\hline
\end{tabular}


Nagu eelnevas näidatud, ajakohastab konversatsiooniagent $A$ argumenteerimisdialoogis oma partnerimudelit $\boldsymbol{w}^{A B}$. Samal ajal peab $A$ argumentide toimel ka $B$ ajakohastama oma mudelit $\boldsymbol{w}^{B}$. Samuti nagu $A$ ei tea $B$ tegelike kaalude väärtusi mudelis $\boldsymbol{w}^{B}$, ei tea ka $B$ tegelikke väärtusi mudelis $\boldsymbol{w}^{A B}$.

Tabelis 2 on näidatud muudatused, mida $B$ peab tegema oma mudelis $A$ argumentide toimel. Siin eeldatakse nagu varemgi, et $A$ iga argument suurendab (või vähendab, sõltuvalt tegevuse aspektist) sihtmärgiks oleva kaalu väärtust ühe ühiku võrra (sama eeldus oli tehtud $A$ puhul $B$ vastuargumentide suhtes). $B$ kasutab arutlusprotseduuri SOOV. Tema algne mudel $\boldsymbol{w}^{B}$ annab negatiivse otsuse. Aga dialoogi käigus ajakohastatud lõppmudelil on otsus positiivne.

Kehtigu eeldus, et $A$ tegutseb nii, nagu näidatud osas 3 (tabel 1). $A$ teeb $B$-le ettepaneku, millele lisatud argument suurendab $B$ algses mudelis kaalu w ${ }^{B}$ (kasulik) (1 võrra). $B$ käivitab oma ajakohastatud mudelis arutlusprotseduuri SOOV, mille eeldus on täidetud: $\mathrm{w}^{B}$ (meeldiv) $>\mathrm{w}^{B}$ (ebameeldiv). Arutlus annab negatiivse otsuse, sest ressursid puuduvad (Mul ei ole sobivat riietust, voor 2). A järgmised lausungid (voor 3) suurendavad kaalu $\mathrm{w}^{B}$ (ressursid) 1 võrra ja kaalu $\mathrm{w}^{B}$ (kasulik) samuti 1 võrra. Konstrueerides oma järgmist, 4 . vooru, käivitab $B$ uuesti arutlusprotseduuri SOOV ja saab jälle negatiivse otsuse. Nüüd võiks ta valida ükskõik millise aspekti oma mudelis, mille kaalu suurendamine või vähendamine ( $A$ järgmiste argumentide toimel) võiks anda positiivse tulemuse. Ta valib selleks kahjulikkuse (Mul võivad tekkida probleemid ülikooliga). Oma vastuses (voor 5) esitab $A$ argumendi, mis vähendab mudelis $\boldsymbol{w}^{B}$ kahjulikkuse kaalu 1 võrra, ja teise argumendi, mis suurendab kasulikkuse kaalu 1 võrra. Kui nüüd $B$ käivitab ajakohastatud mudelis arutlusprotseduuri SOOV, siis saab ta positiivse tulemuse (voor 6). Dialoog lõpeb: $A$ ja $B$ on saavutanud oma ühise suhtluseesmärgi. $A$ suutis veenda $B$-d võtma vastu otsust teha $D$, esitades argumente, mille toimel $B$ ajakohastas oma esialgset arvamusemudelit. Sellist tulemust ta sooviski dialoogi alustades (sest $\mathrm{w}^{B}$ (meeldiv) $>\mathrm{w}^{B}$ (ebameeldiv)), aga ilma $A$ argumentideta poleks tema arutlus selle otsuseni jõudnud.

Siin on eeldatud, et $B$ kasutab püsivalt kindlat arutlusprotseduuri (SOOV), kuigi pärast dialoogi 3. vooru võiks ta kasutada ka protseduuri VAJA nagu $A$, sest sellegi eeltingimus osutub täidetuks (joonis 1, osa 2.1). Lõppmudelil $\boldsymbol{w}^{B}$ annavad nii SOOV kui ka VAJA sellesama positiivse tulemuse. $A$ püüab järjekindlalt $B$ peas käivitada protseduuri VAJA, teadmata, et $B$ kasutab tegelikult protseduuri SOOV.

Olgugi et mudelid $\boldsymbol{w}^{A B}$ ja $\boldsymbol{w}^{B}$ (tabelid 1 ja 2) ei lange suhtluse lõpuks ühte, on nendes $D$ positiivsete (meeldiv, kasulik) ja negatiivsete (ebameeldiv, kahjulik, karistus keelatud tegevuse tegemise eest) aspektide kaalude suhe sarnane.

\section{Arutelu}

Püüdes suunata $B$ arutlust taotletava otsuseni (teha või vastavalt mitte teha tegevust $D$ ), esitab $A$ mitmeid argumente, rõhutamaks $D$ tegemise/tegematajätmise positiivseid ja surumaks alla negatiivseid aspekte. $A$ argumentide valik tugineb, ühelt poolt, $B$ esitatud vastuargumentidele ja teiselt poolt, partnerimudelile. Uut argumenti valides käivitab $A$ arutlusprotseduuri partnerimudelil, veendumaks, et pärast selle argumendi esitamist annab arutlus (tema arvates) positiivse tulemuse. $B$ võib kasutada kas sedasama või mõnda muud arutlusprotseduuri, mille ta käivitab 
iseenda mudelil. Pärast $A$ ja $B$ poolt dialoogi käigus tehtud ajakohastamisi lähenevad need mudelid teineteisele, kuid üldjuhul ei kattu. Sellest hoolimata võivad arutlustulemused olla mõlemal mudelil samad, nagu demonstreerisidki tabelid 1 ja 2.

Seega suudab $A$ veenda partnerit $B$ tegema (vastavalt mitte tegema) tegevust $D$, kui tal on piisavalt argumente $D$ tegemise (mittetegemise) kasuks ja tema algne ettekujutus $B$-st ei erine liiga palju $B$ tegelikest arvamustest. Dialoogi kestel muutuvad osalejate esitatud argumentide mõjul nii $A$ oletatavad arvamused partnerimudelis $w^{A B}$ kui ka $B$ tegelikud arvamused mudelis $w^{B}$.

$A$ ja $B$ algsed eesmärgid võivad ühtida või olla vastandlikud. Vaadeldud dialooginäites oli mõlema osaleja eesmärk sama: et $B$ otsustaks teha $D$. Vastuargumendid, mida $B$ esitas ja mida $A$ suutis tõrjuda, olid tingitud $B$ arvamustest, mida $A$ oma argumentidega suutis muuta.

Käsitletud mudel hõlmab küll üksnes piiratud dialooge, kuid ometi illustreerib olukorda, kus osalejad suudavad argumentide abil muuta teineteise arvamusi ja neid dialoogi käigus omavahel lähendada. Seejuures ei tarvitse dialoogi algataja $A$ teada, kas partneri $B$ vastuargumendid on põhjustatud sellest, et tema eesmärk ongi vastupidine $A$ eesmärgile, või on need lihtsalt takistused ühise eesmärgi saavutamisel, mida $A$ saab oma argumente esitades aidata ületada. $A$ eesmärk seevastu ei ole varjatud. Teiseks, nagu eespool (osas 2.2) mainitud, on $A$ iga suhtlustaktika suunatud teatud kindla arutlusprotseduuri käivitamisele $B$ peas. See ei tarvitse õnnestuda ja $A$ ei pruugi sellest arugi saada (nagu vaadeldud näites, kus $A$ eeldab, et $B$ kasutab arutlusprotseduuri VAJA, kuid tegelikult on see hoopis SOOV). Hoolimata sellest võib $A$ saavutada oma suhtluseesmärgi, kui tal on piisaval hulgal argumente.

Siin vaadeldud argumenteerimisdialoogi formaalne mudel hõlmab üksnes teatud kitsalt piiritletud dialooge, kus on kõne all mingi tegevuse tegemine või tegematajätmine ja tulemuseks on $B$ otsus ( $j a h$ või $e i$ ) tegevuse tegemise kohta. Kui $A$ ja $B$ on üksmeelsed, st nende algne eesmärk on sama, siis jõuavad nad lõpuks ühise kokkuleppeni. See ei tähenda tingimata, et nad saavutavad oma algse suhtluseesmärgi. Näiteks võib juhtuda, et kuigi nii $A$ kui ka $B$ on püstitanud eesmärgi, et $B$ teeks $D$, selgub suhtluse käigus, et $B$ ressursid $D$ tegemiseks on puudulikud ja kumbki osaleja ei suuda leida argumente, mis avaksid võimalusi ressursse juurde hankida. Sellisel juhul jõutakse küll ühise otsuseni (" $B$ ei tee $D$ ”), kuid suhtluseesmärkjääb saavutamata. Mudeli praegune realisatsioon (täpsemalt, suhtlusstrateegiad ja -taktikad) ei käsitle olukordi, kus algset suhtluseesmärki modifitseeritakse, näiteks seatakse $D$ tegemisele teatavad eeltingimused või tehakse tegevus osaliselt. Lihtsustav on ka eeldus, et dialoogis muudab iga argument sihtmärgiks oleva arvamuse kaalu ühe ühiku võrra, sest tegelikkuses ei tarvitse argumendid olla võrdse mõjukusega (ja see sõltub suhtluspartnerist).

Kui $A$ ja $B$ alustavad vastandlike suhtluseesmärkidega, siis on tegu vaidlusega. Vaidlus lõpeb tavaliselt ühe osaleja "võidu" ja teise "kaotusega", st üks osaleja saavutab oma eesmärgi ja teine peab sellest loobuma. Mudeli praegune realisatsioon ei võimalda olukorda, kus dialoogi käigus jõutakse kompromissini algsete eesmärkide vahel, st kus mõlemad pooled teevad järeleandmisi ja muudavad oma eesmärki. 


\section{Kokkuvõte}

Siin vaadeldakse dialooge, kus kaks inim- või tehisagenti $A$ ja $B$ diskuteerivad selle üle, et üks neist $(B)$ teeks (või jätaks tegemata) tegevuse $D$. Nende algsed suhtluseesmärgid võivad ühtida või olla teineteisele vastupidised. Saavutamaks oma suhtluseesmärke, toovad mõlemad esile argumente $D$ tegemise poolt ja vastu. $A$ argumendid põhinevad partnerimudelil ja $B$ argumendid tema iseenda mudelil. Mõlemad mudelid sisaldavad arvamusi $D$ tegemiseks vajalike ressursside olemasolu ning $D$ positiivsete ja negatiivsete aspektide kohta. Nende arvamuste kaalud on mudelites esitatud kui naturaalarvud. Mõlemad mudelid muutuvad dialoogi kestel. Artiklis vaadeldakse juhtumianalüüsi kasutades, millest need muudatused on põhjustatud ja kuidas neid tehakse.

Varem on välja töötatud konversatsiooniagendi mudel, mille koosseisu kuulub arutlusmudel. Arutledes teatava tegevuse tegemise üle, kaalub ja võrdleb subjekt vaadeldava tegevuse erinevaid aspekte. Kui positiivsed aspektid kaaluvad rohkem, siis on otsus "teha tegevus", vastupidisel juhul aga "mitte teha tegevust".

Arvutil on realiseeritud mudeli erijuht, kus suhtlevad dialoogsüsteem ja inimene-kasutaja. Kumbki osaleja valib etteantud loenditest eestikeelseid lauseid, mis on semantiliselt liigitatud. Ühel puhul on arvuti $A$ rollis ja kasutaja $B$ rollis, teisel puhul on rollid vahetatud. Kui arvuti mängib $A$ rolli, siis kasutab ta argumentide valikuks partnerimudelit, mida dialoogi käigus muudab, nagu on kirjeldatud osas 3. Kui arvuti mängib $B$ rolli, siis ta kasutab ja ajakohastab iseenda mudelit, nagu on kirjeldatud osas 4. Inimene-kasutaja ei pea DS-iga suheldes muidugi järgima ühtegi kindlat algoritmi (aga võib seda teha).

Edaspidi oleks huvitav realiseerida arvutil stsenaarium, kus omavahel suhtlevad kaks konversatsiooniagenti, et täpsemalt uurida erinevate arutlusprotseduuride omavahelist mõju seoses arvamuste muutumisega dialoogi käigus.

\section{Viidatud kirjandus}

Amgoud, Leila; Besnard, Philippe; Hunter, Anthony 2015. Representing and reasoning about arguments mined from texts and dialogues. - Symbolic and Quantitative Approaches to Reasoning with Uncertainty, Vol. 9161 of the series Lecture Notes in Computer Science, 6o-71. http://dx.doi.org/10.1007/978-3-319-20807-7 6

Bos, Johan; Klein, Ewan; Lemon, Oliver; Oka, Tetsushi 2003. DIPPER: Description and Formalisation of an Information-State Update Dialogue System Architecture. - Proceedings of the SIGDial Workshop on Discourse and Dialogue, 115-124. Sapporo. http://sigdial.org/workshops/workshop4/proceedings/11 SHORT bos dipper.pdf (4.3.2016).

Jurafsky, Dan; Martin, James H. 2009. Speech and Language Processing: An Introduction to Natural Language Processing, Computational Linguistics, and Speech Recognition. Prentice Hall.

Koit, Mare 2012. Konversatsiooniagendi modelleerimine argumenteerimisdialoogis: suhtlus kui infoseisundite värskendamine. - Eesti Rakenduslingvistika Ühingu aastaraamat = Estonian Papers in Applied Linguistics, 8, 109-122. http://dx.doi.org/10.5128/ ERYa8.07

Koit, Mare 2015. Läbirääkimiste modelleerimine arvutil. - Eesti Rakenduslingvistika Ühingu aastaraamat $=$ Estonian Papers in Applied Linguistics, 11, 127-140. http://dx.doi. org/10.5128/ERYa11.08 
Koit, Mare; Õim, Haldur 2003. Eestikeelse dialoogi modelleerimine. - Keel ja Kirjandus, 10, 721-735.

Koit, Mare; Õim, Haldur 2014a. A computational model of argumentation in agreement negotiation processes. - Argument \& Computation, 5 (2-3), 209-236. http://dx.doi. org/10.1080/19462166.2014.915233

Koit, Mare; Õim, Haldur 2014b. Modelling Debates on the Computer. - Joaquim Filipe, Jan Dietz, David Aveiro (Eds.), Proceedings of the International Conference on Knowledge Engineering and Ontoly Development: 6th International Conference on Knowledge Engineering and Ontoly Development, Rome, Italy. SCITEC Publications, 361-368.

Traum, David R.; Larsson, Staffan 2003. The information state approach to dialogue management. - Jan van Kuppevelt, Ronnie W. Smith (Eds.), Current and New Directions in Discourse and Dialogue. Text, Speech and Language Technology 22. Springer, 325-353. http://dx.doi.org/10.1007/978-94-010-0019-2 15

Young, Steve; Schatzmann, Jost; Thomson, Blaise; Weilhammer, Karl; Ye, Hui 2007. The Hidden Information State Dialogue Manager: A Real-World POMDP-Based System. Proceedings of Human Language Technology Conference of the North American Chapter of the Association of Computational Linguistics, 27-28. Rochester, New York, USA.

Mare Koit (Tartu Ülikool), füüsika-matemaatikakandidaat. On uurinud dialoogi modelleerimist arvutil.

Liivi 2, 50409 Tartu, Estonia

mare.koit@ut.ee 


\section{CHANGING BELIEFS OF PARTICIPANTS \\ IN ARGUMENTATION DIALOGUE}

\section{Mare Koit}

University of Tartu

The paper discusses a model of argumentation dialogue which includes reasoning. Two participants present arguments for and against doing an action by one of them. The choice of an argument depends, on the one hand, on the beliefs about the positive and negative aspects of doing the action and the needed resources, and on the other hand, on the result of reasoning based on these beliefs. The roles of the two participants are different in dialogue. One participant (the initiator) is using a partner model - the hypothetical beliefs about the partner who is aimed to do the action. At the same time, the partner operates with the actual beliefs. Both the models have to be updated during a dialogue and the updates have to be tracked. The examples considered in the paper are taken from the interactions with an experimental dialogue system. In one case, the system initiates a dialogue and attempts to influence the user to make a decision to do (or not) an action. In the other case, the roles of the computer and the user are reversed. Interaction is text-based, and the participants are using ready-made sentences in Estonian which are classified semantically. The paper concentrates on changes of beliefs in both models during a dialogue.

Keywords: argumentation dialogue, reasoning model, beliefs, Estonian 